\title{
Engineering seismic demand in the 2012 Emilia sequence: preliminary analysis and model compatibility assessment
}

\author{
Iunio Iervolino ${ }^{\star}$, Flavia De Luca, Eugenio Chioccarelli
}

Università di Napoli Federico II, Dipartimento di Ingegneria Strutturale, Napoli, Italy

\author{
Article history \\ Received July 20, 2012; accepted August 28, 2012. \\ Subject classification: \\ Ground motion, Seismic risk, Spectra, Intensity measures.
}

\section{Introduction}

The Emilia 2012 sequence featured seven events of moment magnitude $(M)>5$, five of which occurred between May 20 and May 29, 2012. These earthquakes were structurally damaging over a wide area. The damage included partial or total collapse of industrial precast reinforced-concrete structures, historical masonry, and mainly nonstructural damage to reinforced-concrete buildings; see Section 8 (Data and sharing resources) for damage report repository. These structural typologies are, in principle, sensitive to different ground-motion intensity measures. For example, loss of support requires significant displacement demand at relatively long periods, while infilling damage is due to the ground-motion amplitude at higher frequencies, and masonry structures are comparatively more sensitive to the cyclic content of ground shaking. Moreover, because events were concentrated in time and space, it can be argued that the cumulative effects of the sequence contributed to the damage.

As the current seismic code [C.S.LL.PP. 2008] uses a seismic hazard map [Stucchi et al. 2011] to determine the seismic actions for structural design, when a strong earthquake occurs, probabilistic estimates are understandably questioned for their consistency with respect to the observed ground motion. While it is easy to show that in terms of frequency of exceedance of intensity measures, the hazard can hardly be validated via the records of a single earthquake [e.g., Iervolino 2012], on the other hand, it can certainly be verified whether the observations are compatible or atypical with respect to what is predicted by the tools used in best-practice hazard studies.

These issues mostly motivated the preliminary analysis briefly presented in this report; i.e., to investigate the engineering seismic demand (peak and cyclic) and to compare this with the prediction models. Both elastic and inelastic demands were considered. Indeed, the inelastic demands are more important from the structural engineering point of view.

The waveforms considered refer to the M 6 May 20, 2012, and the M 5.9 May 29, 2012, events; i.e., those made available by the national accelerometric network (RAN; Rete Accelerometrica Nazionale); see Section 8. Although several recordings up to hundreds of kilometers from the sources are available, most of this study focuses on five seismic stations that lie within $50 \mathrm{~km}$ of the epicenters of both of these earthquakes (Figure 1, within R1 and R2).

This report is structured such that the peak and integral ground-motion intensity measures are provided first for the five close stations. Subsequently, there is a comparison with several ground-motion prediction equations (GMPEs) for all of the RAN stations up to $650 \mathrm{~km}$ from the epicenters. For the stations closer to the source, the recorded elastic pseudoacceleration response spectra $\left(S_{a}\right)$ are also superimposed on the predictions according to the GMPEs of Bindi et al. [2011], and to the design spectra for $475 \mathrm{yr}$ and $2475 \mathrm{yr}$ return periods $\left(T_{r}\right)$. The inelastic displacement spectra for selected structural systems are given and discussed with respect to recently developed semi-empirical models [i.e., De Luca 2011, De Luca et al. 2012]. The same is carried out with respect to the 'equivalent number of cycles' $\left(\mathrm{N}_{\mathrm{e}}\right)$, a measure of how the ground-motion damaging potential is distributed over the entire waveform [Iervolino et al. 2006]. Finally, the kinematic ductility $(\mu)$ is analyzed to understand whether the sequence was ordinary with respect to the engineering demand. Close records were also checked for forward directivity effects. Finally, the study includes consideration of the cumulative inelastic demands from the two events, to measure the effects of repeated shocks on structures. Indeed, what is presented in the following is based on the more extended reports by Chioccarelli et al. [2012a, 2012b], where further analyses and discussions can be found.

\section{Processing and assumptions}

At the time of the study, limited information was available to the authors with respect to the source geometries. Therefore, in all of the cases in which the closest distance to the fault plane projection $\left(\mathrm{R}_{\mathrm{jb}}\right)$ was necessary, an empir- 


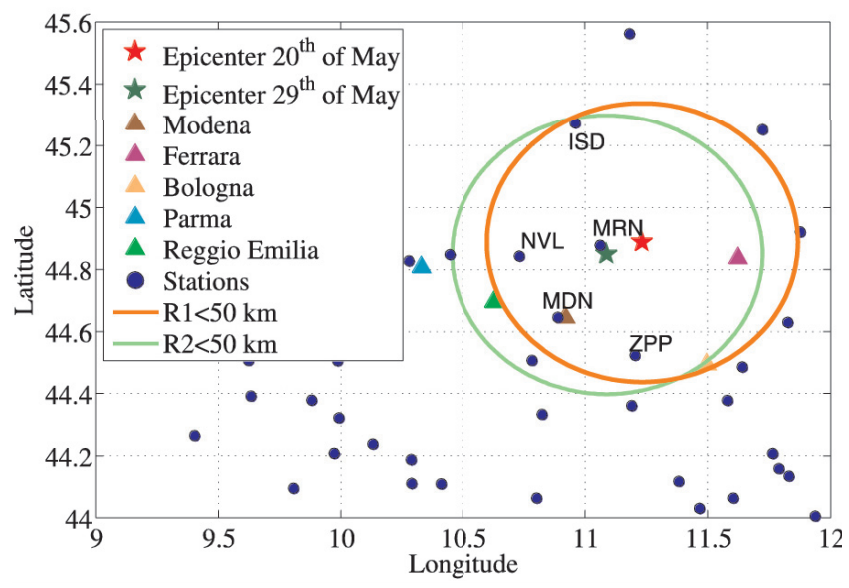

Figure 1. RAN recording stations within ca. $200 \mathrm{~km}$ of the epicenters, and those considered within $50 \mathrm{~km}$.

ically calibrated model [Montaldo et al. 2005], not considering associated uncertainty, was used to convert the epicentral distance $\left(\mathrm{R}_{\text {epi }}\right)$. Moreover, as only a linear baseline correction was originally applied to waveforms by the data provider, the records were further processed by applying a fourth-order bandpass Butterworth filter with a frequency range of $0.25 \mathrm{~Hz}$ to $25 \mathrm{~Hz}$. This procedure does not differ significantly with respect to that used for the Italian Accelerometric Archive (ITACA) [e.g., Pacor et al. 2011].

\section{Peak and cyclic intensity measures}

In this section, the intensity measures of the records considered are analyzed. First, peak ground acceleration (PGA), peak ground velocity (PGV) and $S_{a}$, are compared to the GMPEs of Bindi et al. [2011], for both the May 20, 2012 (Figure 2) and May 29, 2012 (Figure 3) events. The GMPE plots refer to the A-type site class according to C.S.LL.PP. [2008], as the soil classifications were not available to the authors for all of the stations. Even with this approximation, general agreement is seen between the data and the prediction models. Comparisons are reported for the geometric
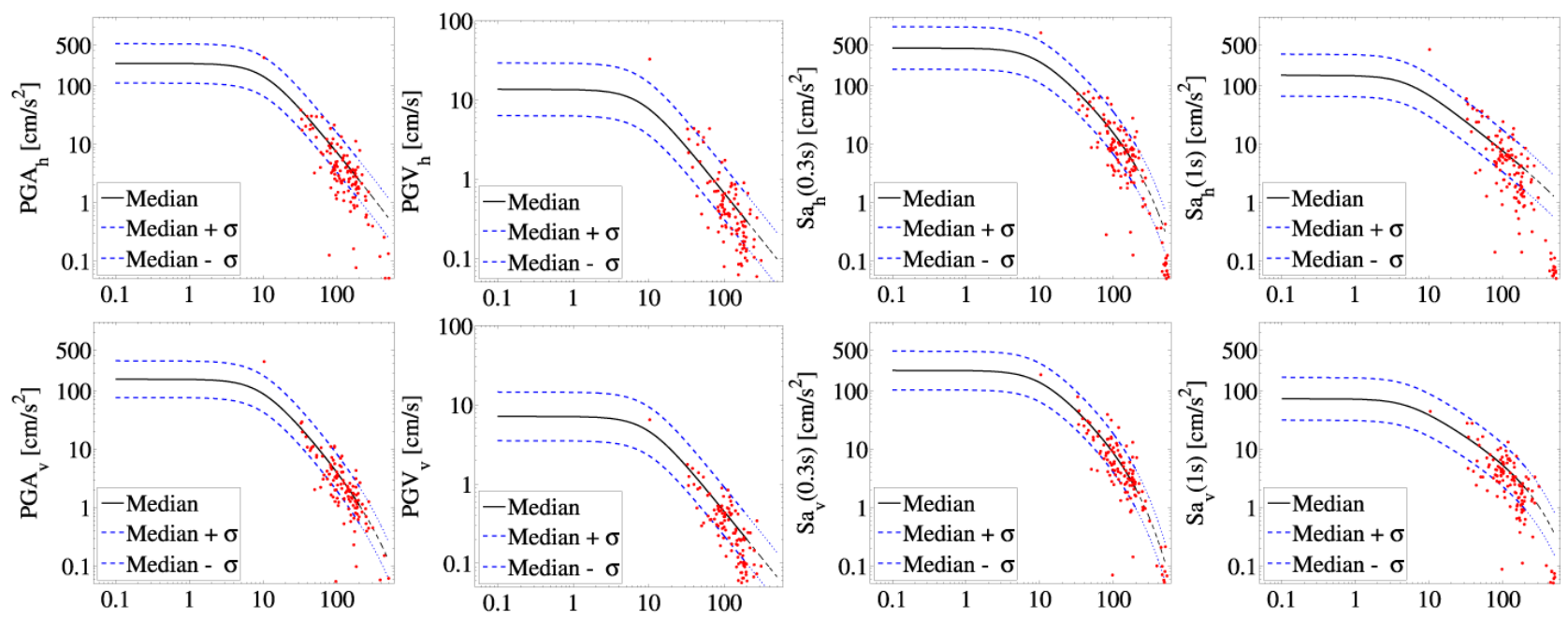

Figure 2. May 20, 2012, event: comparison with the GMPE in terms of PGA, PGV, $\mathrm{S}_{\mathrm{a}}(0.3 \mathrm{~s}), \mathrm{S}_{\mathrm{a}}(1.0 \mathrm{~s})$, for the geometric mean of the horizontal (h subscript) and for the vertical (v subscript) components of ground motion. Horizontal axis: always $\mathrm{R}_{\mathrm{jb}}(\mathrm{km})$.
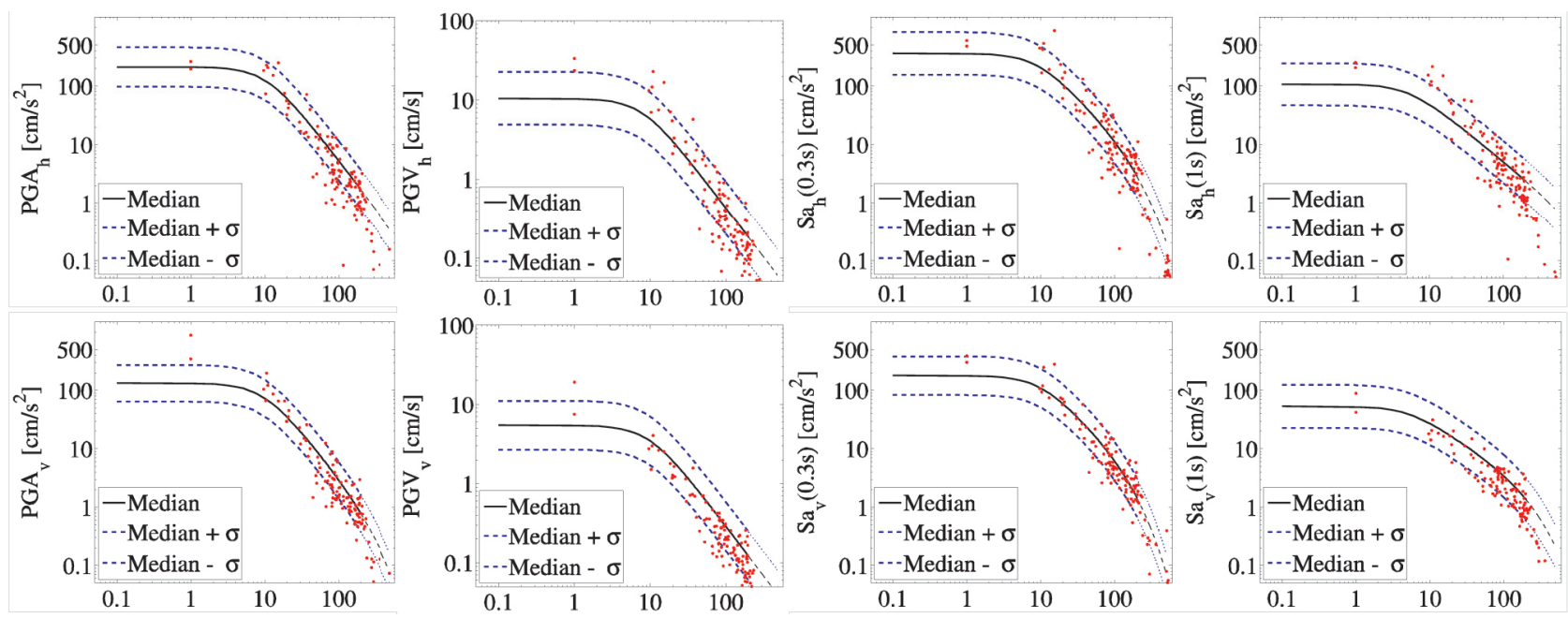

Figure 3. May 29, 2012, event: comparison with the GMPE in terms of PGA, PGV, $\mathrm{S}_{\mathrm{a}}(0.3 \mathrm{~s})$, $\mathrm{S}_{\mathrm{a}}(1.0 \mathrm{~s})$, for the geometric mean of the horizontal (h subscript) and for the vertical (v subscript) components of ground motion. Horizontal axis: always $\mathrm{R}_{\mathrm{jb}}(\mathrm{km})$. 
means of horizontal and for the vertical components of the ground motion. For the sake of brevity, only PGA, PGV and two Sa ordinates at periods $(\mathrm{T})$ of $0.3 \mathrm{~s}$ and $1.0 \mathrm{~s}$ are shown. The GMPE predictions are represented by median values and median plus or minus one total standard deviation (median $\pm \sigma$ ). The interested reader can find these and other comparisons in Chioccarelli et al. [2012a, 2012b], also in terms of the GMPE residuals

The Arias intensity $\left(\mathrm{I}_{A}\right)$ was also considered. The $\mathrm{I}_{\mathrm{A}}$ is the largest among the horizontal components of each record divided by $\pi /(2 \cdot g)$, and it is compared to the GMPE of Sabetta and Pugliese [1996] (Figure 4). In this case, the agreement appears to be of a lower grade; however, several data-points fall outside the applicability range of the GMPEs.

Table 1 summarizes the peak and integral parameters of the ground motion for all of the components of the five records within $50 \mathrm{~km}$ from the epicenters. More specifically, for both events, the reported intensity measures are: PGA, PGV, $\mathrm{I}_{\mathrm{A}}$, Cosenza and Manfredi Index $\left(\mathrm{I}_{\mathrm{D}}\right.$, a measure of the cyclic damage potential of the ground motion [Iervolino et al. 2006]), and Housner Intensity $\left(\mathrm{H}_{50}\right)$.

The local site conditions were obtained from ITACA, except for the ZPP station, for which they were not available. An A-type site class was thus assumed for ZPP.

The 5\% damped elastic pseudo-acceleration response spectra are compared in Figure 5 with the median spectra corresponding to $\mathrm{M}, \mathrm{R}_{\mathrm{jb}}$ and site class $( \pm \sigma)$ from the GMPEs

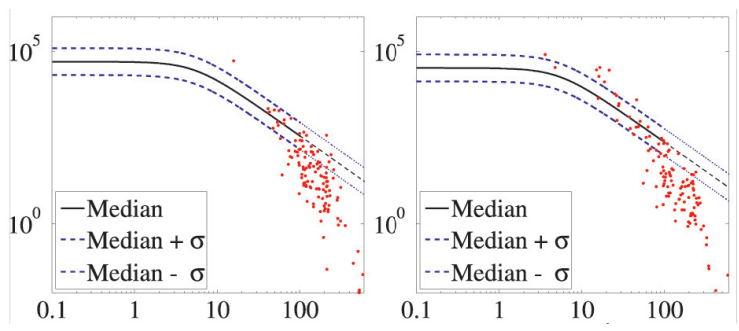

Figure 4. $\mathrm{I}_{\mathrm{A}}$ versus GMPEs, for the May 20 (left) and the May 29 (right), 2012, events. Horizontal axis: always $\mathrm{R}_{\text {epi }}(\mathrm{km})$. Vertical axes are $\mathrm{I}_{\mathrm{A}}$ divided by $\pi /(2 \cdot g)\left(\mathrm{cm}^{2} / \mathrm{s}^{3}\right)$.

of Bindi et al. [2011]. The comparison indicates that the elastic demand in all of the ground-motion components does not appear to be atypical.

\section{Discussion with respect to design spectra}

In Figure 6, the spectra for the MRN station (the closest to both epicenters) is compared to the design spectra, for the A-type and D-type soil classes (as amplitude boundaries) from the Italian code [C.S.LL.PP. 2008]. Those referring to the Atype site class are basically uniform hazard spectra for $475 \mathrm{yr}$ and $2475 \mathrm{yr} \mathrm{T}_{\mathrm{r}}$ (an arbitrary, yet wide, range) from probabilistic hazard; i.e., Stucchi et al. [2011]. At the MRN station, the recorded spectra are comparable or greater than the high $T_{r}$ uniform hazard spectra. This can be interpreted as if the probabilistic hazard underestimates the hazard in the area. However, the Figure 6 clearly shows that the other nearby stations

\begin{tabular}{|c|c|c|c|c|c|c|c|c|c|c|c|c|c|c|}
\hline \multirow{2}{*}{ Station IDs } & \multirow{2}{*}{ Comp. } & \multirow{2}{*}{$S$} & \multicolumn{2}{|c|}{$\mathbf{R}_{\mathrm{epi}}(\mathbf{k m})$} & \multicolumn{2}{|c|}{ PGA $\left(\mathrm{cm} / \mathrm{s}^{\mathbf{2}}\right)$} & \multicolumn{2}{|c|}{$\mathrm{PGV}[\mathrm{cm} / \mathrm{s}]$} & \multicolumn{2}{|c|}{$\mathrm{I}_{\mathrm{A}}(\mathrm{cm} / \mathrm{s})$} & \multicolumn{2}{|c|}{$I_{D}$} & \multicolumn{2}{|c|}{$\mathrm{H}_{50}(\mathrm{~cm})$} \\
\hline & & & 20 & 29 & 20 & 29 & 20 & 29 & 20 & 29 & 20 & 29 & 20 & 29 \\
\hline \multirow{3}{*}{$\begin{array}{l}\text { Mirandola } \\
\text { (MRN) }\end{array}$} & N-S & \multirow{3}{*}{ C } & \multirow{3}{*}{16} & \multirow{3}{*}{4} & 313 & 267 & 45 & 54 & 86.8 & 132.6 & 3.8 & 5.7 & 127.5 & 134.8 \\
\hline & E-W & & & & 295 & 256 & 23 & 21 & 71.4 & 78.9 & 6.4 & 9.3 & 82.4 & 67.7 \\
\hline & V & & & & 317 & 883 & 6 & 19 & 43.6 & 289.9 & 13.2 & 10.8 & 16.0 & 25.7 \\
\hline \multirow{3}{*}{$\begin{array}{l}\text { Modena } \\
(\mathrm{MDN})\end{array}$} & N-S & \multirow{3}{*}{ C } & \multirow{3}{*}{41} & \multirow{3}{*}{28} & 38 & 54 & 4 & 4 & 2.7 & 4.4 & 10.4 & 12.8 & 12.4 & 14.9 \\
\hline & E-W & & & & 39 & 33 & 4 & 3 & 3.5 & 2.8 & 13.0 & 19.1 & 14.0 & 10.4 \\
\hline & V & & & & 28 & 35 & 2 & 2 & 1.3 & 1.8 & 16.4 & 19.1 & 5.4 & 6.5 \\
\hline \multirow{3}{*}{$\begin{array}{l}\text { Novellara } \\
\text { (NVL) }\end{array}$} & N-S & \multirow{3}{*}{ C } & \multirow{3}{*}{42} & \multirow{3}{*}{28} & 48 & 45 & 2 & 3 & 2.6 & 4.8 & 15.6 & 25.2 & 7.1 & 10.1 \\
\hline & E-W & & & & 48 & 55 & 3 & 3 & 2.8 & 5.0 & 13.1 & 21.6 & 7.5 & 10.5 \\
\hline & $\mathrm{V}$ & & & & 29 & 45 & 1 & 1 & 0.9 & 2.6 & 20.5 & 29.7 & 1.6 & 2.3 \\
\hline \multirow{3}{*}{$\begin{array}{c}\text { Zola Pedrosa } \\
\text { Piana (ZPP) }\end{array}$} & N-S & \multirow{3}{*}{ A } & \multirow{3}{*}{43} & \multirow{3}{*}{38} & 21 & 24 & 4 & 3 & 2.7 & 2.1 & 18.9 & 16.7 & 15.5 & 12.7 \\
\hline & E-W & & & & 15 & 24 & 2 & 3 & 1.5 & 1.8 & 27.5 & 16.9 & 9.0 & 9.4 \\
\hline & V & & & & 20 & 23 & 1 & 1 & 0.8 & 0.7 & 21.0 & 15.6 & 4.6 & 3.3 \\
\hline \multirow{3}{*}{$\begin{array}{l}\text { Isola della Scala } \\
\qquad \text { (ISD) }\end{array}$} & N-S & \multirow{3}{*}{ B } & \multirow{3}{*}{47} & \multirow{3}{*}{48} & 16 & 15 & 2 & 2 & 0.9 & 1.1 & 22.4 & 20.4 & 7.0 & 8.3 \\
\hline & E-W & & & & 15 & 12 & 2 & 1 & 0.9 & 0.5 & 23.5 & 19.0 & 7.6 & 4.8 \\
\hline & V & & & & 9 & 7 & 1 & 1 & 0.2 & 0.2 & 17.3 & 21.5 & 2.5 & 2.3 \\
\hline
\end{tabular}

Table 1. Peak and integral intensity measures of the five stations within an epicentral distance $<50 \mathrm{~km}$. E-W, east-west; N-S, north-south (referring to horizontal components); V, vertical component; 20, 29, May 20 and 29, 2012; S, local site conditions; $\mathrm{R}_{\text {epi }}$, epicentral distance; PGA, peak ground acceleration; PGV, peak ground velocity; $\mathrm{I}_{\mathrm{A}}$, Arias intensity; $\mathrm{I}_{\mathrm{D}}$, Cosenza and Manfredi Index; $\mathrm{H}_{50}$, Housner Intensity. 

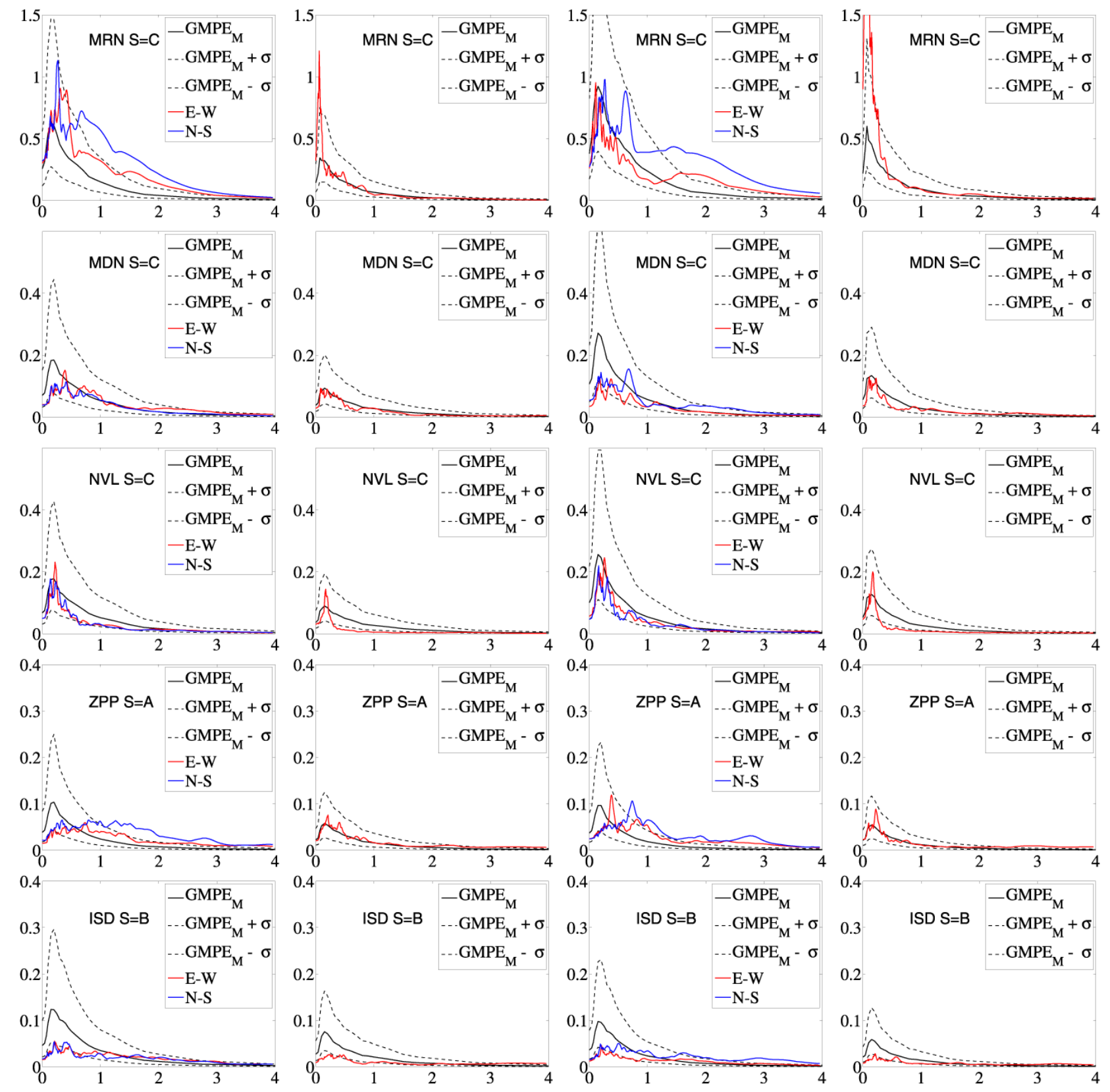

Figure 5. Comparison between GMPE-predicted and actual spectra for the May 20 (first and second columns from the left) and the May 29 (third and fourth columns from the left), 2012, events. First and third columns refer to horizontal components, while second and fourth column refer to vertical components. Vertical axis: always $\mathrm{S}_{\mathrm{a}}(\mathrm{g})$; Horizontal axis: always $\mathrm{T}(\mathrm{s})$.
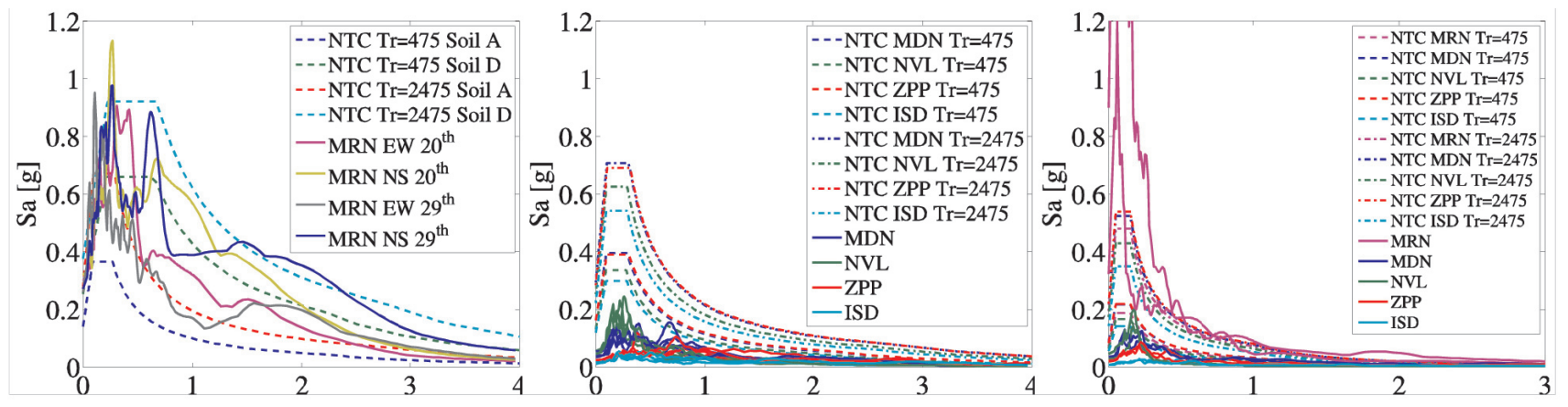

Figure 6. Comparison with code spectra for horizontal components of: MRN station (left), of the other four stations (center), and for the vertical components of all of the stations (right). Horizontal axis: always T (s). (Vertical component of MRN might be affected by instrumental error) [see Mirandola Earthquake Working Group 2012]. 
experienced response spectra that were generally much below the design spectra. Indeed, when the probabilistic hazard is compared to the observed ground motion, the latter is always taken at the maximum value; i.e., as close as possible to the source of the earthquake. This is obvious and is perfectly understandable. However, when arguing about possible underestimations of probabilistic seismic-hazard studies, it needs to be considered that these average (via the total probability theorem) all of the possible epicentral locations. Indeed, the probabilistic hazard computed assuming that the epicenter is the site of interest would certainly be larger than the case where the epicentral location is spread on all possible locations within the source. As during an earthquake, a specific (yet uncertain) site will be the epicenter, a comparison of the recorded spectrum with the probabilistic hazard spectrum for that site only can be misleading, and verification should be carried out also considering other non-epicentral stations [e.g., McGuire and Barnhard 1981, Albarello and D'Amico 2008]. This check for the Emilia events confirms that it is not possible to question the probabilistic hazard solely on the basis of the spectrum at the epicenter (this is also because of the intrinsic limits of GMPEs, especially in the near-source region, and of the uniform hazard spectra, which cannot be addressed herein for the sake of brevity.) On the other hand, to check whether the actual magnitude and source features were appropriately accounted for in the models considered to investigate the hazard, as well as the suitability of the GMPEs used in the analysis (i.e., other comparisons herein), might represent be more appropriate verifications [Iervolino 2012].

\section{Inelastic engineering demand}

For the five close stations, the inelastic peak and cyclic engineering demand parameters (EDPs) were computed because they are especially relevant to the measurement of earthquake damage potential. For this, two different single degree of freedom (SDoF) systems were selected to represent generic nonlinear structures: (a) an elastic-plastic backbone with a nondegrading strain-hardening hysteretic loop (EPP-k); and (b) an elastic-hardening backbone with a hardening stiffness of $5 \%$ of that elastic, and a pinching hysteresis rule (EPH-p) (Figure 7).

For the EPH-p SDoF and considered EDPs, prediction equations were recently developed in terms of the GMPEs of the constant strength reduction factor $\left(\mathrm{R}_{\mu}\right)$ [i.e., De Luca 2011, De Luca et al. 2012]. $R_{\mu}$ is defined in Equation (1), where $\mathrm{F}_{\mathrm{y}}$ is the yield strength, and $m$ is the mass of the SDoF.

$$
R_{\mu}=\frac{S a(T) \cdot m}{F_{y}}
$$

The peak-EDP is the inelastic displacement $\left(\mathrm{Sd}_{\mathrm{R}_{\mu}=\mathrm{i}}\right)$. The inelastic EDP related to the cyclic ground-motion potential is defined in Equation (2); i.e., the equivalent number of cycles. $\mathrm{N}_{\mathrm{e}}$ is given by the cumulative hysteretic energy $\left(\mathrm{E}_{\mathrm{H}}\right)$,
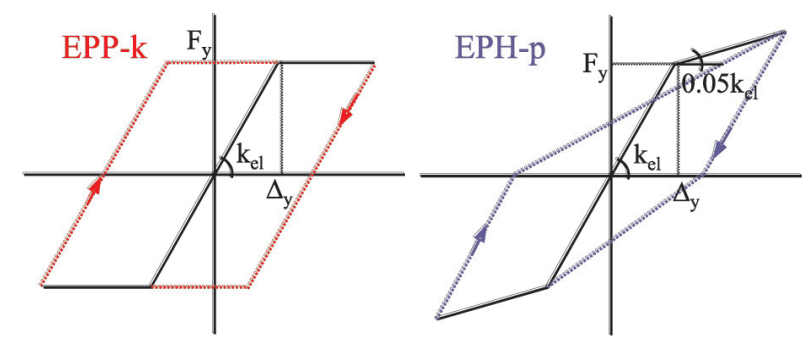

Figure 7. EPH-p and EPP-k SDoF constitutive relationships.

which is computed as the sum of the areas of the hysteretic cycles (not considering the contribution of viscous damping) normalized with respect to the largest cycle; this latter is the area underneath the monotonic backbone curve from the yielding displacement to the peak inelastic displacement $\left(\mathrm{A}_{\text {plastic }}\right)$.

$$
N_{e}=\frac{E_{H}}{A_{\text {plastic }}}+1
$$

In Figure 8, the nonlinear EDP spectra are compared to the corresponding GMPE predictions for EPH-p at an $\mathrm{R}_{\mu}$ of 6. As a benchmark, the elastic spectral displacements, $S \mathrm{~d}_{\mathrm{el}}$, where also computed and compared with the GMPEs by De Luca [2011]. The comparisons were carried out separately for the two events considered. In addition, the cumulative effects of the sequence were computed $\left(20^{\text {th }}+29^{\text {th }}\right)$. As for the elastic comparisons above, the results show general agreement of the recordings with the predictions (except for MRN in a selected period range, and ZPP, which is also likely to be due to the assumed soil conditions).

The peak displacement does not increase significantly for the structure subjected to the series of the two events. Conversely, $\mathrm{N}_{\mathrm{e}}$ is affected by the cumulative effect, which often exceeds the predictions. This means that the series had, as expected, an increased damaging potential for structures sensitive to the cyclic demand of the ground motion, with respect to the two events alone.

Referring to the EPP-k backbone of Figure 7, the demand of the kinematic ductility [Iervolino et al. 2006] was also computed for horizontal records of the five stations within $50 \mathrm{~km}$. The considered SDoF has a fundamental period of $0.5 \mathrm{~s}$ and an $\mathrm{R}_{\mu}$ factor of 6 for the design spectral acceleration at the MRN station, for the D-type site class and a $\mathrm{T}_{\mathrm{r}}$ equal to $475 \mathrm{yr}$; i.e., $0.66 \mathrm{~g}$. The results are summarized in Table 2 for MRN only, because the responses computed for the other stations did not produce any inelastic behavior; i.e., the ductility demand was always zero for that specific system

\begin{tabular}{ccccc}
\hline \multicolumn{2}{l}{ Station and component } & $\mu_{1}$ (May 20) & $\mu_{2}$ (May 29) & $\mu_{1}+\mu_{2}$ \\
\hline MRN & E-W & 5.3 & 3.7 & 8.9 \\
MRN & N-S & 10.4 & 13.8 & 24.2 \\
\hline
\end{tabular}

Table 2. Kinematic ductility demand for the MRN station. 

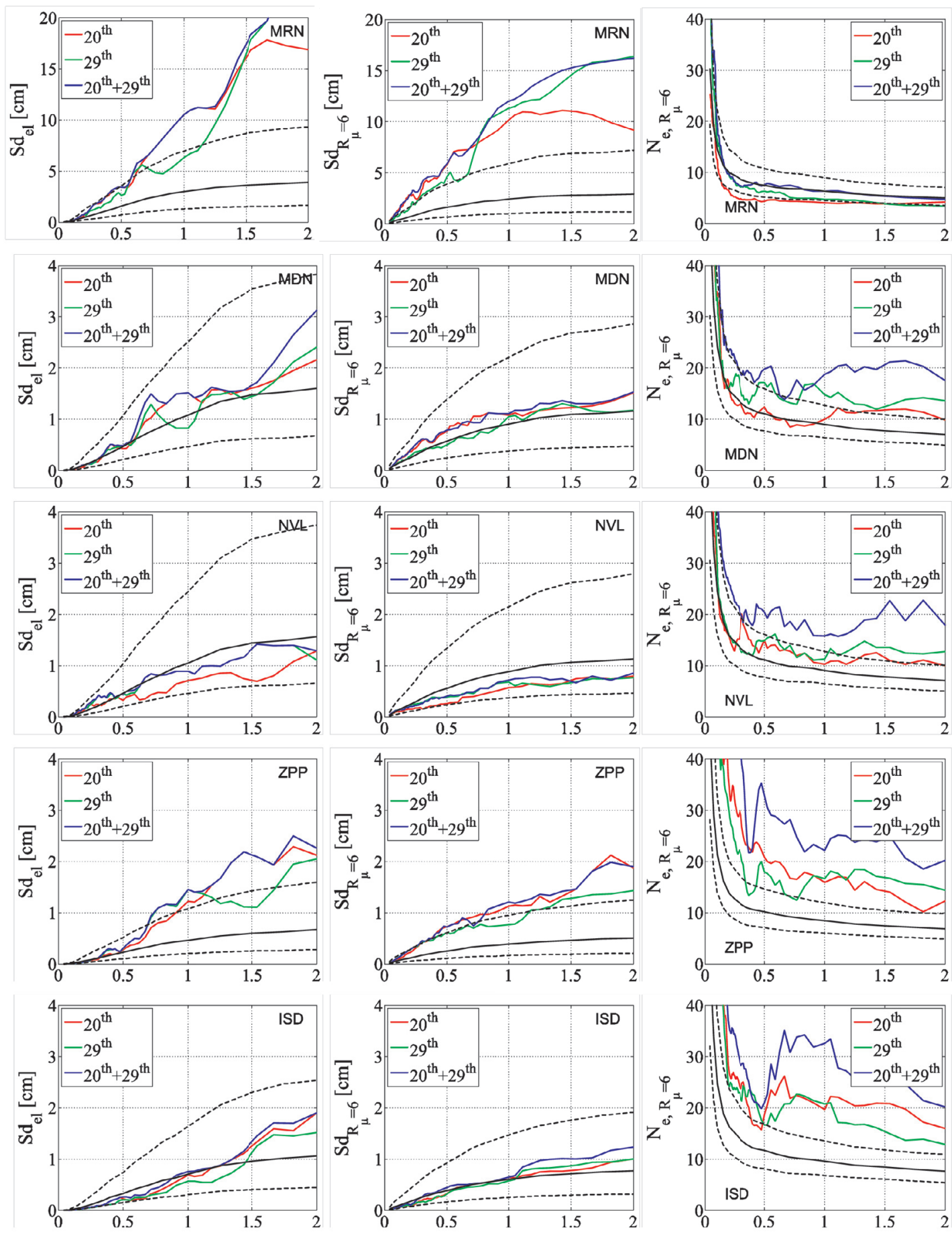

Figure 8. Geometric means of the horizontal elastic and inelastic displacements (first two columns), and equivalent number of cycles spectra (third column) evaluated separately for the two events (May 20 and 29, 2012) and for the sequence $\left(20^{\text {th }}+29^{\text {th }}\right)$, compared with the GMPEs by De Luca [2011] and De Luca et al. [2012], evaluated for magnitude and distance of the May 20 event. Horizontal axis: always T (s).

(consistent with Figure 6, which indicates their somewhat weak motion). On the other hand, the ductility demand at MRN was significant for both events.

\section{Forward directivity check}

The recorded ground motion of the stations within 50 $\mathrm{km}$ from the epicenters was investigated with respect to possible directivity effects. The records were searched for predominant pulses in the velocity time history [e.g., Chioccarelli and Iervolino 2010]. Given that the rupture was unknown, for each station, the time histories were rotated in all of the possible horizontal directions and analyzed. No evidence of forward directivity effects of structural relevance was found; see Chioccarelli et al. [2012a, 2012b] for details.

\section{Conclusions}

A preliminary analysis of the records of the two strongest events in the 2012 Emilia sequence has been presented. The analyses were carried out to determine whether the engineering seismic demand might be considered ordi- 
nary; i.e., somewhat expected for events of this kind. This was carried out mainly for the stations closer to the source, by comparing the recorded responses with the recent prediction models based on Italian datasets. Analyses were carried out in terms of: (1) peak and cyclic ground-motion intensity measures; (2) elastic spectral ordinates; and (3) inelastic peak and cyclic SDoF demands. In the last case, the effects of the seismic sequence were also considered.

The results indicate that generally the recorded ground motions cannot be considered atypical, in terms of elastic and inelastic, and peak and cyclic, demands. It was also shown that, as expected, the seismic series had a significant cyclic and ductility damage potential, when compared to the two events individually. This is especially meaningful considering that the short inter-event time did not allow for the repair of several damaged structures after the first earthquake.

The comparison with design spectra show that the ground motion was comparable, with high return period predictions only at the epicenter. It was also briefly discussed why this is not a sufficient argument to question the probabilistic hazard studies.

Finally, the records were searched for near-source forward directivity effects. The velocity time histories apparently do not show any full velocity cycles of structural engineering interest.

\section{Data and sharing resources}

Records used in this study were made available by the Italian Civil Protection Department (Dipartimento della Protezione Civile Nazionale); the interested reader should refer to Mirandola Earthquake Working Group [2012] for details, at http://www.protezionecivile.gov.it. The soil conditions for some of the recording stations were retrieved from ITACA (http://itaca.mi.ingv.it/). Damage reports for the Emilia sequence are available at http:/ /www.reluis.it/.

Acknowledgements. This study was carried out in the ReLUIS 20102013 Research Programme founded by the Dipartimento della Protezione Civile. The two anonymous reviewers who provided comments that improved quality and readability of the report are gratefully acknowledged.

\section{References}

Albarello, D., and V. D'Amico (2008). Testing probabilistic seismic hazard estimates by comparison with observations: an example in Italy, Geophys. J. Int., 175, 1088-1094.

Bindi, D., F. Pacor, L. Luzi, R. Puglia, M. Massa, G. Ameri and R. Paolucci (2011). Ground motion prediction equations derived from the Italian strong motion database, B. Earthq. Eng., 9, 1899-1920.

Chioccarelli, E., and I. Iervolino (2010). Near-source seismic demand and pulse-like records: a discussion for L'Aquila earthquake, Earthq. Eng. Struct. D., 39, 1039-1062.

Chioccarelli, E., F. De Luca and I. Iervolino (2012a). Preliminary study of Emilia (May 20,2012) earthquake ground motion records V2.11; available at http: / /www.reluis.it Chioccarelli, E., F. De Luca and I. Iervolino (2012b). Preliminary study of Emilia (May 29, 2012) earthquake ground motion records V1.0; available at http: / / www.reluis.it

C.S.LL.PP; DM 14 Gennaio (2008). Norme tecniche per le costruzioni, 2008. Gazzetta Ufficiale della Repubblica Italiana, 29 (In Italian).

De Luca, F. (2011). Records, capacity curve fits and reinforced concrete damage states within a performance based earthquake engineering framework, $\mathrm{PhD}$ thesis, University of Naples Federico II, Department of Structural Engineering, Advisors: G. Manfredi, I. Iervolino, G.M. Verderame; available at http:/ /wpage.unina.it/iuniervo/

De Luca, F., G. Ameri, I. Iervolino, F. Pacor and D. Bindi (2012). Prediction equations for peak and cyclic engineering seismic response based on Italian data, Earthq. Spectra, under review.

Iervolino, I., G. Manfredi and E. Cosenza (2006). Ground motion duration effects on nonlinear seismic response, Earthq. Eng. Struct. D., 35, 21-38.

Iervolino, I. (2012). Probabilità e salti mortali: le insidie della validazione della analisi di pericolosità attraverso l'occorrenza di singoli terremoti, Progettazione Sismica, 2, 3743, IUSS Press, Pavia (in Italian).

McGuire, R.K., and T.P. Barnhard (1981). Effects of temporal variations in seismicity on seismic hazard, B. Seismol. Soc. Am., 71, 321-334.

Mirandola Earthquake Working Group (2012). Reports 1, 2; available at http:/ / www.protezionecivile.gov.it/

Montaldo, V., E. Faccioli, G. Zonno, A. Akinci and L. Malagnini (2005). Treatment of ground-motion predictive relationships for the reference seismic hazard map of Italy, J. Seismol., 9, 295-316.

Pacor, F., R. Paolucci, G. Ameri, M. Massa and R. Puglia (2011). Italian strong motion records in ITACA: overview and record processing, B. Earthq. Eng., 9, 1741-1759.

Sabetta, F., and A. Pugliese (1996). Estimation of response spectra and simulation of nonstationary earthquake ground motion, B. Seismol. Soc. Am., 86, 337-352.

Stucchi, M., C. Meletti, V. Montaldo, H. Crowley, G.M. Calvi and E. Boschi (2011). Seismic Hazard Assessment (20032009) for the Italian Building Code, B. Seismol. Soc. Am., 101, 1885-1911.

\footnotetext{
*Corresponding author: Iunio Iervolino,

Università di Napoli Federico II, Dipartimento di Ingegneria Strutturale, Napoli, Italy; email: iunio.iervolino@unina.it.

(C) 2012 by the Istituto Nazionale di Geofisica e Vulcanologia. All rights reserved.
} 